\title{
A Health Equity Audit of the Diabetic Eye Screening Programmes in Cumbria and the North East
}

\author{
BALSAM AHMAD, ${ }^{1}$ FERGUS NEILSON ${ }^{2}$
}

\begin{abstract}
We report key findings and lessons learned from a health equity audit (HEA) of six National Health Service Diabetic Eye Screening Programmes (NDESPs) in Cumbria and the North East of England. Uptake of diabetic eye screening was analysed in relation to demographic variables including age, sex, socioeconomic deprivation and geography and a combination of these in each of the six NDESPs. A total of 196,275 records of patients with diabetes aged 12 years and over on the NDESP registers were analysed. The key finding was a lower than acceptable screening uptake $(70 \%)$ in the last year among the working age population, especially those living in the most socioeconomically deprived areas. The HEA process also highlighted the need for improvements in collecting data on ethnicity and sex. It informed action plans which address inequities in uptake of screening in each of the six NDESPs, especially those targeting the working age populations and individuals who never attended screening or never responded to screening invitations. We established a method of extracting the patient data from the local systems, pseudonymising and linking to lower super output area. This will be important for HEAs to become embedded in routine practice.

Br J Diabetes 2019;19:42-44
\end{abstract}

Key words: Health Equity Audit; NHS Diabetic Eye Screening Programmes; uptake of screening; diabetic retinopathy;

Cumbria and the North East of England

\section{Introduction}

Diabetic retinopathy is the second most common cause of certifiable vision impairment in the working age population in England

Specialty Registrar in Public Health, Public Health England; and Associate Lecturer in Public Health, Institute of Health and Society, Newcastle University, UK

2 Senior Screening and Immunisation Manager, Public Health England, Newcastle upon Tyne, UK

Address for correspondence: Mr Fergus Neilson Senior Screening and Immunisation Manager, Public Health England, Waterfront 4, Newburn Riverside, Newcastle upon Tyne NE15 8NY, UK E-mail: Fergus.neilson@nhs.net

https://doi.org/10.15277/bjd.2019.203 and Wales. ${ }^{1}$ There is evidence supporting the effectiveness of the NHS Diabetic Eye Screening Programme (NDESP). ${ }^{2}$ Despite this evidence and generally good uptake rates, the overall uptake rates can mask large variations between certain areas or population groups. Factors associated with lower screening uptake include: living in areas of high socioeconomic deprivation, young age, having a long duration of diabetes, poor glycaemic and blood pressure control or belonging to Black Asian and Ethnic Minority (BAME) groups. $^{3}$

NHS England has a statutory duty to reduce inequities in access to healthcare services in relation to the services it commissions. ${ }^{4} \mathrm{~A}$ health equity audit (HEA) is a useful tool to assess equity in access to relevant health services and how this is distributed across population groups and areas relative to need. ${ }^{5}$ It also helps identify priority areas to reduce health inequities. The lead author of this paper was asked to undertake the HEA on behalf of the local NHS England Public Health Commissioning team.

The six NDESPs in Cumbria and the North East of England are part of the NDESP in England, which offers annual screening to all patients with diabetes aged 12 years and over. In this paper we report key findings and lessons learned from the process of undertaking HEA of DESPs in Cumbria and the North East in 2015-16.

\section{Data and method of analysis}

The first stage of the HEA involved a retrospective, secondary analysis (undertaken by the first author) of all eligible patients registered in the six NDESPs in Cumbria and the North East. A total of 196,275 records of patients with diabetes on the NDESP registers were analysed. The analysis was conducted and presented separately for each individual NDESP.

Records were excluded if one of the key variables was missing. Other exclusions included:

- Patients under the care of the Hospital Eye Service for diabetic retinopathy.

- Records of patients in prison. These were analysed separately (analysis not shown here).

Each of the six NDESPs used the EMIS Health OptoMize patient management software. The Programme Managers used the standard 'Performance Report' to extract and export the patient data to an Excel file. The first author gave standard instructions on how to link postcode to lower super output areas (LSOAs) and how to pseudonymise the records. The Office for National Statistics Postcode Lookup files were used to link patient level postcodes to LSOAs. This also provided a deprivation score for each LSOA. 
The data collection and analysis complied with information governance requirements of the NDESPs and those of NHS England. Analysis for each NDESP was undertaken by age band, gender, socioeconomic deprivation (by national quartiles) and a combination of these in relation to the screening uptake rate in the last 12 months which was approximated as follows:

- Numerator: HEA NDESP Data 'On Register and Eligible' (number of patients who received an invitation and attended a screening test in the last 12 months ( $\leq 365$ days)

- Denominator: HEA NDESP Data 'On Register and Eligible'. Microsoft Excel (Version 10) was used in the analysis.

\section{Results}

The overall rate of uptake of screening in the last 12 months in the six NDESPs exceeded the acceptable standard for the national Key Performance Indicator for Uptake (ie, 70\%). Table 1 shows the number screened and uptake for each band of screening in each of the six NDESPs in Cumbria and the North East of England in 2015-16.

Three NDESPs exceeded the achievable standard of $80 \%$.

Table 1 Number screened and uptake of screening within a specified time period in each of the NHS Diabetic Eye Screening Programmes (NDESPs) in Cumbria and the North East ${ }^{6}$

\begin{tabular}{lllllll}
\hline & $\begin{array}{l}\text { NDESP1 } \\
\mathbf{n}(\%)\end{array}$ & $\begin{array}{l}\text { NDESP2 } \\
\mathbf{n}(\%)\end{array}$ & $\begin{array}{l}\text { NDESP3 } \\
\mathbf{n}(\%)\end{array}$ & $\begin{array}{l}\text { NDESP4 } \\
\mathbf{n}(\%)\end{array}$ & $\begin{array}{l}\text { NDESP5 } \\
\mathbf{n}(\%)\end{array}$ & $\begin{array}{l}\text { NDESP6 } \\
\mathbf{n}(\%)\end{array}$ \\
\hline $\begin{array}{l}12 \\
\text { months }\end{array}$ & $\begin{array}{l}38,267 \\
(77 \%)\end{array}$ & $\begin{array}{l}\text { 24,937 } \\
(84 \%)\end{array}$ & $\begin{array}{l}41,758 \\
(78 \%)\end{array}$ & $\begin{array}{l}16,371 \\
(82 \%)\end{array}$ & $\begin{array}{l}15,582 \\
(83 \%)\end{array}$ & $\begin{array}{l}19,005 \\
(78 \%)\end{array}$ \\
$12-15$ & 2127 & 1249 & 3227 & 1067 & 1301 & 1301 \\
months & $(4 \%)$ & $(4 \%)$ & $(6 \%)$ & $(5 \%)$ & $(7 \%)$ & $(5 \%)$ \\
$16+$ & 5664 & 2754 & 6885 & 1794 & 1280 & 3027 \\
months & $(11 \%)$ & $(9 \%)$ & $(13 \%)$ & $(9 \%)$ & $(7 \%)$ & $(13 \%)$ \\
$\begin{array}{l}\text { Never } \\
\text { screened }\end{array}$ & 3973 & 876 & 1759 & 650 & 502 & 920 \\
& $(8 \%)$ & $(3 \%)$ & $(3 \%)$ & $(3 \%)$ & $(3 \%)$ & $(4 \%)$
\end{tabular}

Between $4 \%$ and $7 \%$ of patients were screened in response to the invitation after 12 months but before 15 months. Between $7 \%$ and $13 \%$ of patients were screened in response to the invitation after 15 months. We did not analyse exactly when these patients finally came for screening. This could have been any number of months after their previous screening/invitation. The proportion identified as having never attended ranged from $3 \%$ to $8 \%{ }^{6}$

A socioeconomic gradient in screening uptake rates in the last 12 months was observed in all NDESPs. Overall, large discrepancies in screening uptake were observed in the same age band between those living in the most socioeconomically deprived quartiles nationally (Q1) and the least socioeconomically deprived (Q5).

The uptake of screening in the last 12 months was lower than the acceptable level of $70 \%$ in those aged $19-44$ years in all NDESPs.

Table 2 is an illustration from NDESP1 of the variations found in the uptake of screening in the last 12 months by age and socioeconomic status. ${ }^{6}$

In all NDESPs except NDESP1, the uptake rates in younger females (12-34 years old) were lower than those in males in the comparable age groups.

The process of data collection and analysis in the HEA was useful to highlight the following issues: ${ }^{6}$

- Difficulties highlighted by NDESP managers in extracting nonidentifiable patient data for non-routine analyses.

- Missing and incomplete data on ethnicity, hence screening uptake in relation to ethnicity was not explored.

- Difficulties in extracting some necessary data fields (eg, sex) as a result of missing and incomplete data on the sex category (ie, male/female because only the title of the patient (eg, Mr, Mrs) was possible to retrieve in the data extract. Hence, the sex of patients had to be inferred from the title field, which in some records was not specific enough to allow for inferring the sex field (eg, Dr, Rev).

\section{Discussion}

The key finding was low screening uptake in the working age

Table 2 Screening uptake rate in last 12 months (2015-16) in NDESP1 by age band and national socioeconomic quintiles Q1 (most socioeconomically deprived quartiles nationally) and Q5 (least socioeconomically deprived quartiles nationally) ${ }^{6}$

\begin{tabular}{|c|c|c|c|c|c|c|c|c|}
\hline $\begin{array}{l}\text { Age } \\
\text { bands } \\
\text { HEA }\end{array}$ & $\begin{array}{l}\text { Number } \\
\text { screened } \\
\text { in last } \\
12 \text { months } \\
\text { in Q1 }\end{array}$ & $\begin{array}{l}\text { Number } \\
\text { on NDESP } \\
\text { register } \\
\text { in Q1 }\end{array}$ & $\begin{array}{l}\text { Screening } \\
\text { uptake (\%) } \\
\text { in last } \\
12 \text { months } \\
\text { in Q1 }\end{array}$ & $95 \% \mathrm{Cl}$ & $\begin{array}{l}\text { Number } \\
\text { screened } \\
\text { in last } \\
12 \text { months } \\
\text { in Q5 }\end{array}$ & $\begin{array}{l}\text { Number } \\
\text { on NDESP } \\
\text { register } \\
\text { in Q5 }\end{array}$ & $\begin{array}{l}\text { Screening } \\
\text { uptake (\%) } \\
\text { in last } \\
12 \text { months } \\
\text { in Q5 }\end{array}$ & $95 \% \mathrm{Cl}$ \\
\hline $12-18$ & 36 & 58 & $62 \%$ & $42.11 \%, 80.53 \%$ & 39 & 52 & $75 \%$ & $51.17 \%, 95.39 \%$ \\
\hline $19-24$ & 44 & 105 & $42 \%$ & $30.14 \%, 54.24 \%$ & 28 & 41 & $68 \%$ & $43.28 \%, 90.17 \%$ \\
\hline $25-34$ & 146 & 298 & $49 \%$ & $41.15 \%, 56.86 \%$ & 28 & 60 & $47 \%$ & $30.38 \%, 63.35 \%$ \\
\hline $35-44$ & 373 & 736 & $51 \%$ & $45.57 \%, 55.79 \%$ & 96 & 164 & $59 \%$ & $46.88 \%, 69.81 \%$ \\
\hline $45-54$ & 1163 & 1913 & $61 \%$ & $57.30 \%, 64.25 \%$ & 435 & 599 & $73 \%$ & $65.71 \%, 79.24 \%$ \\
\hline $55-64$ & 2048 & 2887 & $71 \%$ & $67.85 \%, 73.97 \%$ & 968 & 1189 & $81 \%$ & $76.22 \%, 86.41 \%$ \\
\hline $65-74$ & 2495 & 3123 & $80 \%$ & $76.74 \%, 82.97 \%$ & 1545 & 1783 & $87 \%$ & $82.28 \%, 90.87 \%$ \\
\hline $75-84$ & 1504 & 1907 & $79 \%$ & $74.85 \%, 82.77 \%$ & 1194 & 1424 & $84 \%$ & $79.03 \%, 88.48 \%$ \\
\hline $85+$ & 334 & 473 & $71 \%$ & $62.95 \%, 77.94 \%$ & 351 & 453 & $77 \%$ & $69.23 \%, 85.27 \%$ \\
\hline
\end{tabular}




\section{Key messages}

- National Health Service Diabetic Eye Screening Programmes are effective in reducing the prevalence of blindness in England

- Good overall uptake rates for diabetic eye screening in Cumbria and the North East mask variations in factors such as socioeconomic deprivation and age. A persistently low screening uptake in the working age population, especially in the most socioeconomically deprived areas, was found

- Health equity audit is a useful tool to address inequalities and to prioritise resources in the planning of strategies and action plans that reduce health inequities

population, especially those living in the most socioeconomically deprived areas.

The findings from this HEA highlighted the key priorities for action that could yield the greatest potential improvement in equity of NDESPs in Cumbria and the North East of England. In 2016/2017 a Commissioning for Quality and Innovation incentive was introduced in Cumbria and the North East to stimulate initiatives to analyse and improve uptake in the age group $19-44$ years. ${ }^{6}$ Also, each new initiative to be implemented in Cumbria and the North East would have an audit/evaluation component. The NDESPs were facilitated to work together and learn from the experience in different programmes by the Screening and Immunisations Team.

Other specific actions that were agreed included: 6

- Targeting workplaces to increase knowledge and communicate benefits of screening or specific screening interventions.

- Seeking patient feedback through surveys to explore reasons for lack of attendance for screening in the identified low uptake groups.

- Improving data recorded and consistencies in data quality for future HEAs - for example, in recording data on BAME, sex categories and type of diabetes and include those in the future HEA planned for January 2019.

- Increasing patient awareness of sight-threatening diabetic retinopathy by making every contact count in primary care to encourage attendance in diabetic retinopathy screening and raise awareness about the benefits of screening.

Some examples of initiatives undertaken by the NDESPs include:

- Large, multiple booked clinics for persistent did not attend/ did not respond (DNA/DNR) patients

- Invitation letter on coloured paper
- A survey of the DNA/DNR patients

- Texting

- Direct calls to patients on the day they DNA

It is notable that the uptake measure, screened in the last 12 months, does not fully describe the propensity of patients to attend in response to invitation. The results in Table 1 also showed that several patients attended in the 12-15 months and 16+ month periods. This was in response to their annual invitation, but through a combination of patient choice and programme factors they had a slightly delayed screening. Actions to address inequalities and improve uptake should take this information into account as this helps define the populations and nature of the intervention needed.

\section{Conflict of interest: None}

Funding: No specific additional funding was identified to undertake this work, as work on identifying and addressing inequalities is a core responsibility of the organisations and staff involved. Staff resources were directed to this work as a priority. The staff time used came from the lead author, a Public Health Registrar in the North East Public Health Training Programme, the local Public Health England Screening and Immunisations Team, the PHE Knowledge and Intelligence Team and the local diabetic eye screening programme staff.

Acknowledgement: The authors would like to acknowledge the contribution of the managers of NHS DESPs in Cumbria and the North East: Cumbria, North Lancashire, Blackpool Flyde and Wyre, Sunderland and South Tyneside, North of Tyne and Gateshead, County Durham and Darlington, North Tees, South Tees. We would also like to acknowledge the following people for their contribution and support in data collection and analysis: Rachel Fisher Thompson (PHE), Richard Lamb (Cumbria DESP), Dr David Landes (PHE) and Dr Anna Christie (LKIS, PHE).

\section{References}

1. Liew G, Michaelides M, Bunce C. A comparison of the causes of blindness certifications in England and Wales in working age adults (16-64 years), 1999-2000 with 2009-2010. BMJ Open 2014;4:e004015 https://doi.org/10.1136/bmjopen-2013-004015

2. Scanlon PH. The English National Screening Programme for diabetic retinopathy 2003-2016. Acta Diabeto/ 2017;54:515-25. https://doi.org/ 10.1007/s00592-017-0974-1

3. Leese GP, Boyle P, Feng Z, Emslie-Smith A, Ellis JD. Screening uptake in a well-established diabetic retinopathy screening program: the role of geographical access and deprivation. Diabetes Care 2008;31:2131-5. https://doi.org/10.2337/dc08-1098

4. NHS England. Guidance for NHS commissioners on equality and health inequalities legal duties. 14 December 2015. https://www.england.nhs.uk/ wp-content/uploads/2015/12/hlth-inqual-guid-comms-dec15.pdf (accessed 14 February 2019)

5. Department of Health. Health Equity Audit. A guide for the NHS. https://webarchive.nationalarchives.gov.uk/20130315173148/http://www.dh.gov.uk/ prod_consum_dh/groups/dh_digitalassets/@dh/@en/documents/digitalasset/dh_4084139.pdf (accessed 14 February 2019)

6. PHE and NHS England. Health Equity Audit (HEA) of the NHS Diabetic Eye Screening Programmes (NDESPs) in Cumbria and the North East. Report. 2015-2016 (available from corresponding author on request). 